\title{
Language Cognitive Strategy Analysis in Learner Diaries of College Freshman Students in Kalinga State University, Philippines
}

\author{
Dr. Sheila Fesway-Malao ${ }^{1}$, Brenda Banggawan Lumines ${ }^{2}$
}

\author{
${ }^{1}$ Department of Language, Kalinga State University, Philippines \\ ${ }^{2}$ College of Education, Kalinga State University, Philippines
}

Received: 30 Oct 2020; Received in revised form: 05 Dec 2020; Accepted: 17 Dec 2020; Available online: 31 Dec 2020 (C2020 The Author(s). Published by Infogain Publication. This is an open access article under the CC BY license (https://creativecommons.org/licenses/by/4.0/).

\begin{abstract}
The study analyzed the language cognitive strategies found in learner diaries of college freshman students of Kalinga State University (KSU). Specifically, it determined the cognitive strategies employed by the learners in writing their diaries. The diary of each student was used to elicit the different cognitive strategies employed by the students. The cognitive strategies were classified based on the model of Richard (1975). The data gathered were identified, analyzed, and interpreted using the qualitative-descriptive method. It was found out that: (1) errors committed by the students are intralingual or developmental errors caused by the structure of the second or target language; (2)the students utilized varied cognitive strategies such as overgeneralization, ignorance of rule restriction, incomplete application of rules and false concepts hypothesized in their diaries; and (3) the errors committed by the students were not all influenced by the first language but by the complexity of the target language itself. Thus,(1) errors are considered inevitable in second language learning; the commission of errors is indicative of the interlanguage status of student; and (2) errors are developmental which can be overcome as the students reach a higher interlanguage stage of learning a second language.
\end{abstract}

Keywords - Learner Diaries, English language, Kalinga State University.

\section{INTRODUCTION}

English language learning is crucial in any educational system since learning a language, like learning any skill, is basically a personal achievement, an exploitation and exploration of the capacities of the mind to understand and function in one's environment. Language education is replete with numerous theories with the aim of reaching the goal of understanding language and language learning process. Educators play a crucial role in language instruction. Their focus is not simply to teach the language but also to understand how language can foster acquisition and learning.

Language learning is one of the central topics in cognitive science. Every theory of cognition has tried to explain it; probably no other topic has aroused such controversy. Nonetheless, learning a first language is something every learner does - successfully, in a matter of a few years and without the need for formal lessons. With language so close to the core of what it means to be human, it is not surprising that learners' acquisition of language has received so much attention. Anyone with strong views about the human mind would like to show that learners' first few steps are steps in the right direction. In today's language learning, many students cannot express themselves well in written and oral English. College students are linguistically handicap in an age marked by computers and other high-tech learning tools, as well as a window to foreign cultures opened by media. As Gonzales cited (1998), our students today are ill-equipped for life in a world where communication skills are crucial to communication growth, if not survival. Gonzales further pointed out that, "spotted a decline in the capacity of Filipino students to absorb new knowledge and skills when they reach college." Alarmed by this decline in the quality of education in the Philippine educational system, he offered various suggestions on how to improve quality of education for Filipinos. In the same vein, Duenas (2013) 
noted the deterioration in the proficiency in written English communication is evident in the poor results of the professional and other types of examinations.

The Kalinga State University, a higher educational institution enables a student to graduate with a college degree equivalent to a Bachelor of Science. Forming part of this curriculum is the core curriculum that offers general education courses mandated by the Commission on Higher Education (CHED). Included in this core curriculum are the English courses that aim to equip the students with the basic and essential communication skills- both written and oral- to enable them to perform their jobs well as professionals. Unfortunately, there seems to be a perception that all is not well with the communication skills and communicative competence of the KSU students, and even among its graduates. This seeming weakness of the KSU students in language use has, for fact, come under attack by some sectors in the society. There is indeed a dire need to train and develop KSU students so that they could compete not only with the higher institution in the Philippines but can be able to compete in the ASEAN Integration even if the Philippines is a developing country. One of the essential qualities toward ASEAN Integration is proficiency in the use and command of the English language.

From the foregoing, these researchers deemed it urgent and exigent to study the language cognitive strategies of a group of students whose language proficiency may have an impact upon the country's language policy. Along this line, these researchers chose to conduct a study relevant to the language cognitive strategy problems of KSU students. Language learners are in themselves the cause of the errors especially if they live in a country where English is taught as a foreign language; they obviously do not have adequate exposure to the target language. Opportunities to use English in both the productive and receptive areas of the language are limited and it could give rise to errors in the areas of grammar, lexis, spelling, and punctuation.

Ali (2004) argued that the teacher may not be a good model of the language with regard to the way he speaks, writes, or teaches the language. This is particularly true in Philippine setting because most language teachers are not native speakers. Some errors are ironically teacher induced. Another factor is the teaching method, which may also be at fault for overemphasizing one aspect of the language and neglecting the other. For example, some teachers are fond of only emphasizing the oral component of a course and the learner's general speaking ability would improve but he may lag behind in listening, reading and writing. The context of learning such as misleading explanation and faulty presentation of textbook among others is another source of error (Brown, 2000).

Language learners use cognitive strategies in communicating the second language. These strategies may be systematic or non-systematic technique employed by the learner to express his meaning when faced with some difficulty because of his inadequate command of the language used in the interaction or communication process. Richards (1975) advocates four common learner's cognitive strategies, these are overgeneralization, violation of rule restrictions, incomplete application of rules, and hypothesizing false concepts._Overgeneralization is the strategy used by language learners where they tend to simplify and regularize the linguistic complexities peculiar to the target language. Overgeneralization covers instances where the learner creates a deviant structure on the basis of his experience of other structures in the target language. The learner relies on the target language rule of great generality and which he already knows and avoids learning the appropriate rule. Violation of the rule restriction is the learner's failure to observe restrictions of the existing structures in the target language. Some of the rule restriction errors may arise in terms of analogy as in misuse of prepositions. The learner applies some rules to contexts where they do not apply hence the deviant structure.

Incomplete application of rules is deviations which represent the degree of the rules required to produce acceptable utterances. To a certain extent, rules are applied but their applications are still incomplete. The learner, for instance, has not fully mastered the passive construction. In hypothesizing false concepts, the errors reflect the general characteristics of rule internalization or this category results from the faulty comprehension of distinctions in the target language. The learner at various stages of learning makes a series of hypotheses which he tests and abandons or preserves. For example, is/are may be interpreted as a marker of the present. Hufana and Minong's (1983) study reveals that college freshmen have not fully reached the native speaker's competence as shown in the errors which fall into some kind of regularity. They are errors typically committed by second language learners. The findings further revealed that their performance data demonstrate the learning strategiesovergeneralization, hypothesizing false concepts, incomplete application of rules, and ignorance of rule restrictions- they employed when confronted with a range of communicative tasks. Furthermore, this study asserted that the commission of error should not be considered as a "sin," rather, it should be considered as inevitable and an 
essential part in the learning process, thereby, driving the point that error correction should be an integral part of classroom instruction.

Catimo's (1999) "Linguistic Errors in the Written English of the Student Teachers in the College of Education of Saint Louis University" revealed that the errors committed by the student teachers were attributed to overgeneralization, ignorance of rule restrictions, incomplete application of rules, and false concepts hypothesized.

Viewing writing as an act of communication suggests an interactive process which takes place between the writer and the reader via text. Such an approach places value on the goal of writing as well as on the perceived reader audience. According to Olshtain (1989), the skill of writing enjoys special status - it is via writing that a person can communicate a variety of messages to a close or distant, known or unknown reader/s.

A written data used as basis of language analysis is the learner diary. Learner diary is a first-person account of the language learning documented through regular, candid entries in a personal journal and then analyzed for recurring patterns or salient events. These are daily writings about experiences, memories, and events in the life of a person.

Learner diaries have been proposed as one way of systematizing self-assessment of students. Learners are encouraged to write about what they learned, their perceived level of mastery over the subject, and what they plan to do with their acquired skills.

A learner diary is where a language learner can write down his thoughts on what he has learned during a specific period. Its main aim is to help language learner reflect on the learning process and in particular on which strategies seem to work best for him. What he writes down is totally a question of personal choice depending on the questions asked by the teacher (Riley, 2015).Learner diaries provide the teacher with invaluable insights into what the students think of the lessons, what they understood and what problems they are having. The fact that the teacher has a private and individual learning relationship with each student can have a very positive effect on student behavior and class control, as the teacher can have a discrete means of finding out about and addressing the causes of behavioral problems.

Peachy (2006), claims that learner diaries at its best should be a private dialogue between a student and the teacher. It does not have to be about the learning process only, but can be about almost anything that the learner would like to know or discuss. The most important thing is that it is a real communication and that the teacher responds to the students in an authentic way within this dialogue. The teacher shares his genuine thoughts and opinions with the students rather than simply correcting their grammar and spelling.

In setting up a learner diary, Peachy further states that the teacher writes a few questions for the students to answer. The questions will be classroom related items and outside classroom related items. From the students' answers, the teacher will draw inferences as to the reasons of the perceptions of the students based on the questions asked.

Deen (2011), states that learner diaries play a role in defining a personal philosophy of teaching. The diaries allow teachers to examine language learning or teaching experiences and conduct a kind of self-assessment such as clarifying their thoughts and feelings about these experiences and their way of handling language learning related problems.

For students, a learner diary provides an opportunity for self-analysis since it gives them a chance to reflect on their difficulties and achievements. For the teacher, the chance to write comments in the diaries provides the opportunity to interact with students on an individual basis, which in turn appears to have a positive effect on their behavior and motivation. Students, accustomed previously only to learning situations in which they played a passive role, are slowly beginning to change their attitudes towards their own learning. The students' constructive criticism of lessons becomes a valuable source of feedback, which has had a great effect on the teacher's planning for the subsequent classes (Usuki, 2009).

One of the uses of learner diary studies is to clarify issues. These issues emerge when one looks at the data again and again - to see what is included, what is left out, what kind of language is used, what kind of perspective is taken, what kind of reactions are noted, what kind of tone is adopted, what kind of connectors are made, what the cumulative weights are, what the parts add up to, what projections can be posited, and what cycles can be revealed.It is important, however, to note that a teacher will only get from the learner diaries what he prepared to put in. If the teacher writes openly and honestly to the students, generally the students will do the same. Likewise, if the teacher's responses are minimal and superficial, the same will be the response of the students. Generally, learner diaries is beneficial both to the students and to the teacher, particularly with the latter because he can possibly elicit errors committed by the students on the particular subject. They are, however, very time 
consuming and they will not work for everybody all the time, so it is just as well to have them as an experiment and not to have too high expectations of what can be achieved the first few times (Peachy, 2006).

Thus, the main objective of the study is to analyze the language cognitive strategies found in learner diaries of college freshman students in Kalinga State University (KSU).

Specifically, it determined the language cognitive strategies employed by the learners in writing their diaries, and demonstrate that errors committed by the students were not all influenced by the first language but by the complexity of the target language itself.

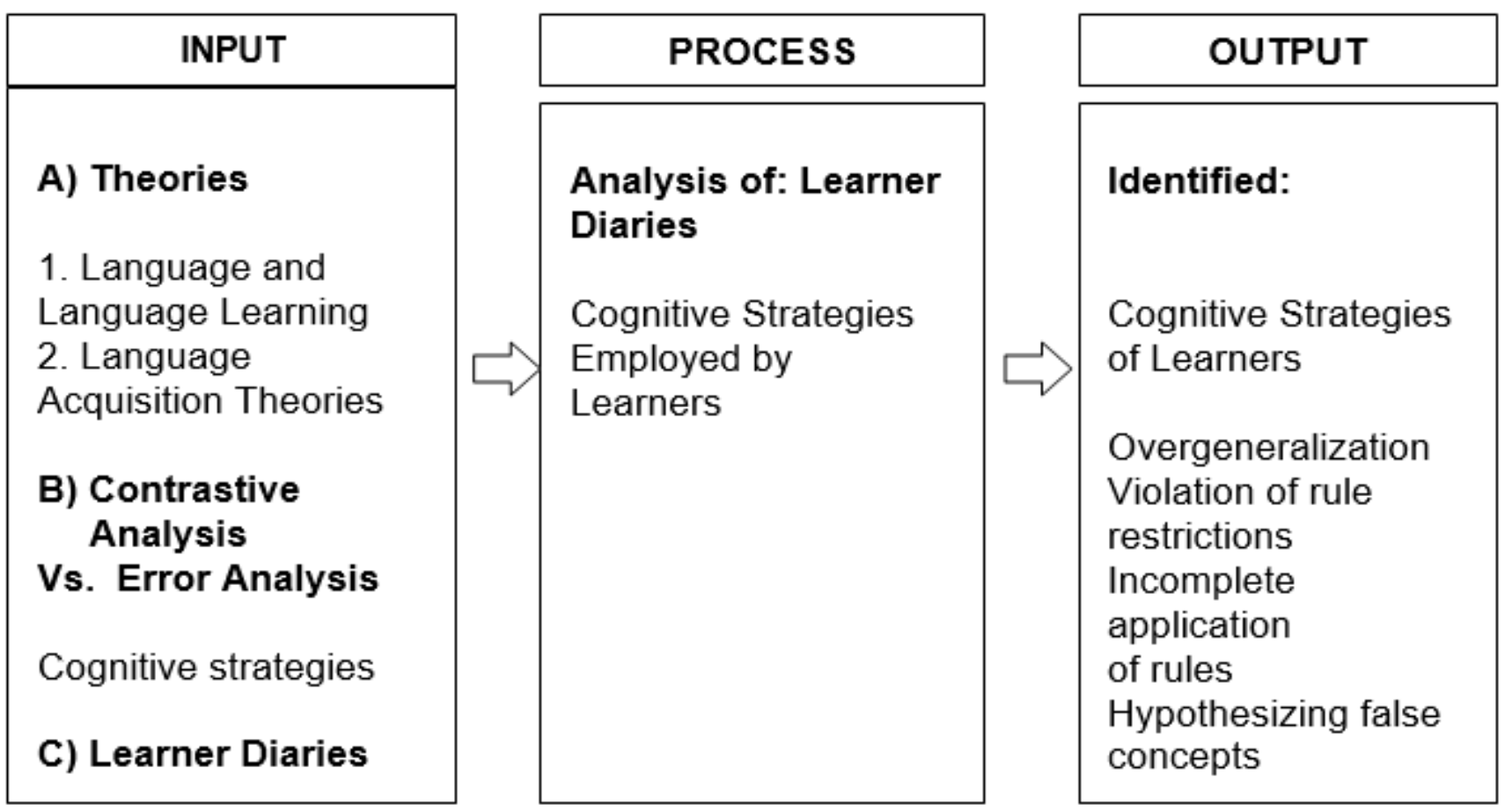

Fig.1: Paradigm of the Study

\section{METHODOLOGY}

The search paper was conducted in the five (5) institutes of Kalinga State University (KSU), Tabuk City, Kalinga, Philippines. These are the Institute of Liberal Arts (ILA), Institute of Business Administration, Public Administration and Entrepreneurship (IBAPAE), Institute of Teacher Education (ITE), Institute of Agriculture and Forestry (IAF), and Institute of Engineering Information and Applied Technology (IEIAT).This research is qualitative- descriptive. It analyzed, described and demonstrated the language cognitive strategies found in learner diaries of college freshman students in KSU. The researchers used the diary of each student to elicit the different cognitive strategies committed by the students based on Richard's model (1975).

The student- respondents of this study were 293 college freshman students from the five (5) institutes of KSU enrolled in English 2 (Writing in the Discipline). The researchers applied the stratified sampling technique, where, the distribution of the 293 number of students in the 19 different major courses across five (5) Institutes, were identified as follows: Institute of Liberal Arts (60), Institute of Business Administration, Public Administration and Entrepreneurship (62), Institute of Teacher Education (29), Institute of Agriculture and Forestry (47), and Institute of Engineering Information and Applied Technology (95).

Sample student population was chosen using the Sloven's Formula:

$n=\frac{\mathrm{n}}{1+\mathrm{Ne}^{2}}$

level

$\begin{array}{lll}\mathrm{n} & = & \text { sampling population } \\ \mathrm{N} & = & \text { whole population }\end{array}$

e $=$ standard error at .05 
Friedman's test showed the following formula:

$$
\mathrm{X}^{2}=\frac{12}{\mathrm{~N} \mathrm{~K}(\mathrm{~K}+1) \sum(\mathrm{R})-3 \mathrm{n}(\mathrm{K}+1)}
$$

The respondents answered a set of guide questions as a basis for writing their diaries regarding classroom related factors (Cohort 1). From their written comments and reactions, the cognitive strategies employed by the learners in writing their diaries were analyzed using the model of Richards (1975).

The questionnaires were administered (cohort 1) twice a week in English 2 classes on Tuesdays and Thursdays at 1 $1 / 2$ hours a day to enable the students to write something in their diaries.

The data gathered were identified, analyzed, and interpreted using qualitative descriptive treatment. The college freshman students wrote their diaries based on a set of questions asked. From these diaries, errors produced were elicited for analysis.

The analysis was qualitative rather than quantitative for the reason that there were evidences where two strategies overlap. The strategies were classified based on the Model advocated by Richards (1975), namely: overgeneralization, ignorance of rule restriction, incomplete application of rules, and false hypothesized concepts.

\section{RESULTS AND DISCUSSION}

Cognitive Strategies Employed by the College Freshman Students in their Diaries

Language learners use cognitive strategies in communicating in the second language. These strategies may be systematic or non- systematic technique employed by the learner to express his meaning when faced with some difficulty because of his/her inadequate command of the target language used in the interaction or communication process. Richards (1975) claims that deviant forms produced by second language learners are not only caused by the interference of the learner's mother tongue but originate within the structure of the target language itself. These errors which he calls intralingual or developmental errors reflect the learner's competence at a particular stage of learning. In this context, the learner uses some strategies in his attempt to communicate in the target language.

This portion of the study presents the cognitive strategies employed by the respondents. The main objective of the analysis was to demonstrate or show that errors committed by the students were not all influenced by their first language but by the complexity of the target language itself. Thus, the analysis was qualitative rather that quantitative because there were evidences where two strategies overlap. For instance, an error may be due to ignorance of rule restriction or overgeneralization as shown in the following sentences.

When our instructor see wrong doing of us in the classroom...

When our instructor sees wrong doing of us in the classroom...

She use a variety in techniques and approaches.

She uses varied techniques and approaches.

The above sentences are examples of overgeneralization; that is the learner demonstrates that the present tense formation involves a zero morpheme as in "instructor see" and "she use...."

On the other hand, the above sentences illustrate his ignorance of rule restriction. It violates the restriction of concord or SV agreement.

The data presented herein are excerpts from the students' diaries. The errors were classified within the framework advocated by Richards (1975), namely: overgeneralization, violation of rule restrictions, incomplete application of rules, and hypothesizing false concepts.

\section{Overgeneralization}

This kind of error results from the learner's attempt to simplify and regularize the linguistic complexities peculiar to the target language. For example, in the sentences:

\section{Our teacher give varied activities.}

Our teacher gives varied activities.

For the topics are discuss in class, I finds it very interesting.

For the topics that are discussed in class, I find it very interesting.

She use varieties of techniques approaches...

She uses varied techniques approaches...

Our teacher encourage us students...

Our teacher encourages us students...

This demonstrates that the learner's rule for the present tense formation involves using a zero morpheme to mark number for all persons. However, the target language 
rule says that all present tense verbs for all persons except the third person singular requires $-\mathrm{s}$, the morpheme has been reduced to a rule which requires a zero morpheme for all persons. Duskova (1999) accounts for this omission as a result of the heavy pressure of all other ending less forms.

Other examples of this kind of errors are found in the following sentences:

She present the lesson in a well-organized and easy-tounderstand manner.

She presents the lesson in a well-organized and easy-tounderstand manner.

Our instructor organize lectures, recitations, and discussion logic.

Our instructor organizes lectures, recitations, and discussion logically.

The instructor speak slow but clearly.

The instructor speaks slow but clear.

On the other hand, errors on the opposite direction are shown below:

The activities provides participation.

The activities provide participation.

The topics challenges me to attend the class every meeting. The topics challenge me to attend the class every meeting.

The discussions motivates me to prepare.

The discussions motivate me to prepare.

The noises makes her get angry easily.

The noises make her gets angry easily.

Varied activities gets me excited all the

time.

Varied activities get me excited all the

time.

These errors are ascribed as hypercorrection as being due to generalization of the third person singular number for the third person plural.

\section{Ignorance of Rule Restrictions}

This type of error is the learner's failure to observe restrictions of the existing structures in the target language. For instance, some of the rule restriction errors may arise in terms of analogy as in misuse of prepositions. The learner in encountering a particular preposition with one type of verb tries by analogy to use the same preposition with similar verb as in the sentence.
Here are some examples:

Also she is good mood and to all of us in good atmosphere.

She is in good mood to all of us so the atmosphere is also good.

Here the expression "good mood" is always as a rule preceded by the preposition "in" this "in good mood".

Yes on certain times, our instructor relates the topic in real life situation.

Yes, on certain times, our instructor relates the topic to real life situation.

The phrase "relates the topic" as a rule uses the preposition to which indicates a relation or reference to a particular thing: real life situation.

The teacher is related our lesson of real life and to exist condition...

The teacher relates our lesson to real life and to existing condition...

Of course there was a learning on something in the lesson that is of importance and relevant in my English 2 class.

Of course we learned something in the lesson that is important and relevant in our English 2 class.

In the above sentence, important is used be parallel with relevant. That is two adjectives are joined to show parallelism.

Yes, I learned something off important in research.

Yes, I learned something of important in research.

The use of off is incorrect for what the learner meant was "of importance," or phrase commonly used. In the above context the rule is of + noun.

In the similar manner, the learner having learned the structure can be classified into, can be divided into or can be grouped into in realizing classification used by instead of into in the sentence.

We discussed in research writing the parts of the research paper can be divided $\underline{\text { by... }}$

We discussed in research writing the parts of the research paper can be divided into...

We can be grouped by during

class activities.

We can be grouped into during class activities.

Our lesson in English can be classified by many sub topics.

Our lesson in English can be classified into many sub topics. 
Another instance where the learner fails to observe restrictions in the article usage is the omission of the article the before nouns made particular in the context.

It is the responsibility of $\wedge$ students to

listen or not.

It is the responsibility of the students to

listen or not.

The lecture of ^^teacher was long and...

The lecture of the teacher was long and..

In my English 2 class $\_$topics are few

and interesting.

In my English 2 class the topics are few but interesting.

The article a is used instead of the before the plural noun in a sentence like:

I did not like a suggestions of my board mates like sharing in expenses.

I did not like the suggestions of my board mates like sharing in expenses.

Our instructor distributes $\underline{a}$ photocopies needed in our lesson.

Our instructor distributes the photocopies needed in our lesson.

She discusses a lessons with a loud voice.

She discusses the lessons with a loud voice.

I appreciates $\underline{a}$ activities

prepared by our teacher.

I appreciate the activities prepared by our teacher.

The article $a$ is omitted before class nouns defined by an adjective is another example of the learner's failure to observe restrictions in articles as in:

The teacher delivering the lesson with ${ }^{\wedge}$ objective style.

The teacher is delivering the lesson with an objective.

The lesson in research is $\wedge$ very relevant topic.

The lesson in research is a very relevant topic.

What I can say is that she has ${ }^{\wedge}$ good command of the English language.

What I can say is that she has a good command of the English language.

Of course there was $\wedge$ good raport among us.

Of course there was a good rapport among us.

The use of the instead of $\underline{a}$ before an adjective is another instance of the article misuse as in:
That shows her evidence of the thorough

preparation.

That shows her evidence of $\underline{a}$ thorough

preparation.

logical manner.

She has discussed the lesson in the

She has discussed the lesson in a logical

manner.

The activity given by the teacher is the true to life situation.

The activity given by the teacher is a true to life situation.

Violation in the restriction of concord is demonstrated in the following:

Lessons is well organized by the

instructor.

instructor.

$$
\text { Lessons are well organized by the }
$$

The activities is a true to life situations.

The activities are true to life situations.

Sometimes, in our lesson our instructor relate the topic of our lesson to real life situation.

Sometimes, our instructor relates the topic of our lesson to real life situation.

Our teacher have good sense of humor...

Our teacher has a good sense of humor...

Another violation in the verb system is the violation of the limitations of the - $\underline{\text { ed }}$ after be + past participle as exemplified in the following sentences:

complete.

Our seatwork need more time to be

Our seatwork need more time to be completed.

The assign task given the teacher, more time is needs.

The assigned task given by the teacher needed more time.

She is prepare when she comes to class.

She is prepared when she comes to class.

Her methodologies are admire by her class.

Her methodologies are admired by her class.

The lessons were present well and interestingly.

The lessons were presented well and interestingly.

Good answers are recognize by our instructor.

Good answers are recognized by our instructor.

The subject matter is integrate with real life situations. 
The subject matter is integrated with real life situations.

\section{Incomplete Application of Rules}

Errors of this type indicate that to some extent rules are applied; but their application is incomplete. For example, the learner has not fully mastered the passive formation which is formed by the be + past participle. Thus, be is omitted as illustrated in the following deviant sentences:

The activities that ${ }_{-}^{\wedge}$ given is quite difficult because there is the time pressure.

The activities that were given is quite difficult because there is the time pressure.

The research that ${ }_{\perp}$ assigned by the teacher more time to do is needed.

The research that was assigned by the teacher needed more time to be done.

Nothing, I could say due to the topics that $\wedge$ gave by our teacher was in our own field of specialization.

Nothing, I could say because the topics that were given by our teacher were in our own field of specialization.

The research paper that ${ }_{-}$require to us was quite fulfill.

The research paper that was required to us was quite fulfilling.

The tasks which ^ given by the teacher is challenge to me

The tasks which are given by the teacher are challenging to me.

\section{False Concepts Hypothesized}

Errors falling under this category reflect the general characteristics of rule internalization. In the process of hypothesis testing, for example, the learner interprets is / are as markers of the present, thus the following deviations:

The teacher $\underline{\text { is provide }}$ an atmosphere conducive to learning.

The teacher provides an atmosphere conducive to learning.

Our instructor is shows a refinement of manners.

Our instructor shows a refinement of manners.

She is answers students' inquiry intelligent.

She answers students' inquiry intelligently.

Our teacher is relates our lesson to real situations.

Our teacher relates our lesson to real situations.
For our teacher, she is teaches with a well-modulated voice.

For our teacher, she teaches with a well-modulated voice.

The activities are provide a participation of all.

The activities provide a participation of all..

In the above sentences, Richards (1975) contends that in the classroom context, the teacher or the textbook can lead the learner to make faulty hypotheses about the language which George (2005) calls as induced errors. That is, students make errors because of a misleading explanation from the teacher, faulty presentation of a structure or word in a textbook or even a pattern memorized but not properly contextualized.

The analysis of errors presented in this study, yield potentially interesting information. They are deviations typically committed by anyone learning English as a second language. The data also reflect the general characteristics of rule learning indicative of the regular and systematic application of rules, strategies and hypothesis testing.

The study of Hufana and Minong (1983) revealed that their respondents, the college freshmen have not fully reached the native speaker competence as shown in the deviant sentences in the dicto-comp exercises. The findings further revealed that their performance data demonstrate the learning strategies employed by the students when confronted with a range of communicative tasks. Furthermore, the study asserted that the commission of error should not be considered a "sin" rather, it should be considered as inevitable and an essential part in the learning process.

Catimo's (1999) study in the College of Education in Saint Louis University revealed that errors of student-teachers were attributed to the cognitive strategies they employed in their written composition.

Moreover, it can be concluded that a second language learner uses "communicative strategies", propounded by Dulay and Burt (2013) to explain the origin of certain types of errors. This highlights the principle which Corder (1978) calls "risk-taking strategies" which a learner employs when confronted with the task to communicate in the second language. For second language teaching, this implies that the learner should be encouraged to take risks even at the expense of committing errors. More importantly, the teacher should demonstrate willingness to accept errors as a sign of motivation for learning or a strategy of learning. Holly and King (2013) aptly stated that a case can be made for permitting and even encouraging foreign language students to produce 
sentences that are ungrammatical in terms of full native competence. This would allow the learner to progress like a child by forming a series of increasingly complete hypothesis about the language.

\section{CONCLUSIONS}

(1) Errors are considered inevitable in second language learning. The commission of errors is indicative of the interlanguage status of students.

(2) That errors are developmental which can be overcome as the students reach a higher interlanguage stage of learning a second language.

(3) Developmental errors are caused by the difficulty of the structure of the target language. Language teachers need to be aware of the sources as of errors in the different cognitive strategies employed by students. This will aid teachers to determine what and when errors be corrected.

\section{REFERENCES}

[1] ALI, M. H. 2014. Contributory Factors to Students' Errors, with Special Reference to Errors in Written English. International Islamic University. http://www.melta.org.my/ET/1996/main4.html. Accessed on December 2015.

[2] BROWN, D. 1987. Principles of Language Learning and Teaching, 2nd ed. New Jersey: Prentice Hall.

[3] CATIMO, E. 1999. Linguistic Errors in the Written English of the Student Teachers in the College of Education of Saint Louis University. Unpublished Master's Thesis: Saint Louis University, Baguio City.

[4] CHOMSKY, N.1965. Aspects of the Theory of Syntax. Minnesota: Cambridge University Press.

[5] CHOON, T. 2014. Error Analysis and Correction of Written Work in the Classroom. Language Lecturers' and Teachers' Seminar. ITM, Melaka. http://www.cels.bham.ac.uk/resources/essays/farooq2.pdf. Accessed on November 2015.

[6] CORDER, S. 1978. The Significance of Learner's Errors. Error Analysis, ed. J. Richards. London: Longman.

[7] DEEN, J. 2011. A Teacher's Manuscript Diary Study of an Experiment in Project Based Language Learning Unpublished Manuscript. TESL Master's Program, University of California, Los Angeles.

[8] DUENAS, M. 2013. "Low Grade for Public Schools," Philippine Free Press, Vol. LXXXII, No.25.

[9] DULAY, H. \& M. BURT. 2013. Errors and Strategies in Child Second Language Acquisition. TESOL Quarterly.

[10] GEORGE, H. 2005. Common Errors in Language Learning. Rowley, Mass.: Newbury House Publishers.

[11] GONZALES, A. 1998. "English is not Spoken Here," Philippine Daily Inquirer.
[12] HAMADA, I. 2001. An Error Analysis of Written Compositions in Four Rhetorical Acts by PMA Fourth Class Cadets. Unpublished Master's Thesis, Saint Louis University, Baguio City.

[13] HENDRICKSON, J. 1976. Effects of Error Correction Treatment upon Adequate and Accurate Communication in Written Composition of Adult Learners of English as a Second Language. Unpublished Dissertation, Ohio State University, Ohio, USA.

[14] HOLLY, F. \& J. KING. 2013. Imitation and Correction in Foreign Language. In New Frontiers in Second Language Learning, eds. J. Sohumann and N. Stenson. Rowley, Mass.: Newbury House Publishers.

[15] HUFANA, E. 1982. Evaluation of Composition Errors in Rhetorical Acts used in Agricultural Science by Freshman College Students. Unpublished Dissertation, Saint Louis University, Baguio City.

[16] HUFANA, E. \& B. MINONG. 1983. Errors Committed by MSAC Freshmen in Dicto - comp exercises. PES Forum.

[17] HYMES, D. 1971. Communicative Competence in Sociolinguistics .An Interactional Handbook of the Science of Language and Society. Ed. Ulrich Ammon - Berlin de Gruyter.

[18] LADO, R. 2007. Linguistics Across Cultures: Applied Linguistics for Language Teachers. Michigan: University of Michigan.

[19] LARSEN-FREEMAN, D. \& M. LONG. 1991. An Introduction to Second Language Acquisition Research. New York: Longman.

[20] LEE, W. 1995. Thoughts on Contrastive Linguistics in the Context of Foreign Language Teaching. Washington DC: Georgetown University Press.

[21] MYLES, J. 2006. Second Language Writing and Research: The Writing Process and Error Analysis in Student Texts. Queen's University, California.

[22] OLSHTAINE, E. 1989. Is Second Language Attrition the Reversal of Second Language Acquisition? Studies in Second Language Acquisition. London: Longman Group Ltd.

[23] PEACHY, N. April 2015. Learner Diaries. British Council.www.teachingenglish.org.uk. Accessed December, 2015.

[24] RICHARDS, J. 1974. Error Analysis: Perspectives on Second Language Acquisition. London: Longman Group Ltd.

[25] RICHARDS, J. 1975. 'Error Analysis and Second Language Strategies'. In Richards, J.C. and Oller, J.W. (eds), Focus on the Learner. Rowley MA: Newberry House.

[26] RICHARDS, J. , J. PLATT, \& H. WEBER. 1985. Longman Dictionary of Applied Linguistics. London: Longman

[27] RILEY, K. $20015 . \quad$ Learner Diaries. http://people.lett.unitn.it/riley. Accessed on January,2016.

[28] SAVIGNON, S. 2012. Communicative Competence: Theory and Classroom Practice. Reading, MA: AddisonWesley Publishing Company. 
[29] SIBAYAN, B. 2005. "Philippine Language Planning Agenda in the $21^{\text {st }}$ Century," Language Education Council of the Philippines, Malolos, Bulacan.

[30] USUKI, M. 2009. The Usefulness of Learning Diaries in Learner Training. KOKUSAI KOURYUU Center, Hokuriku University, 1-1 Taiyougaoka, Kanazawa-shi, Japan. Translated by Trevor Hughes Parry.

[31] WILKINS, D. 1974. Second Language Learning and Teaching. London: Edward Arnold. 